\title{
Genotype and environment interaction and stability analysis for seed yield in yellow mung bean (Vigna radiata $\mathrm{L}$.)
}

\section{B. Arunkumar* and C. R. Konda}

Agricultural Research Station, Bidar, Raichur- 585102 (Karnataka), INDIA

*Corresponding author. E-mail: b.arunkumar@rediffmail.com

Received: August 21, 2014; Revised received: October 16, 2014; Accepted: December 08, 2014

Abstract: Nine yellow seeded mung (Vigna radiata L.) genotypes were evaluated along with three checks for their yield performance during three years $(2007,2010$ and 2011). Pooled analysis of variance and stability analysis were performed. The genotypic $(G) \times$ environment $(E)$ interaction and both variance due to genotypes and environment were significant. The portioning of $G \times E$ interaction into linear and non-linear components indicated that both predictable and unpredictable components shared the interaction. On the basis of stability parameters, the top yielding genotypes such as BGS-9 $(605.444 \mathrm{Kg} / \mathrm{Ha})$, Sel-4 $(519.778 \mathrm{Kg} / \mathrm{Ha})$ and China mung $(567.000 \mathrm{Kg} / \mathrm{Ha})$ exhibited high mean yield. Based on stability parameters the genotypes YM-5 (459.889 Kg/Ha), YM-8 (451.333 Kg/Ha) exhibited low mean performance along with regression value nearer to unity $(b i=1)$ and non significant deviation from regression $\left(S^{2} \mathrm{di}=0\right)$ indicating the high stability and wider adaptability across the three environments. The genotypes BGS-9 $(605.444 \mathrm{Kg} / \mathrm{Ha})$ and Sel-4 $(519.778 \mathrm{Kg} / \mathrm{Ha})$ exhibited high mean value and bi values (bi>1) and non significant deviation $\left(\mathrm{S}^{2} \mathrm{di}<0\right)$ value indicating adapted for high performance environments (These genotypes are sensitive to environments and give maximum yield when inputs are not limited).

Keywords: $G \times E$ Interaction Green gram, Seed Yield, Stability analysis, Vigna radiata ( L.) and Yellow mung

\section{INTRODUCTION}

Mung bean [Vigna radiata (L.) Wilczek], one of the Asiatic species is an important grain legume in Karnataka. Yellow mung, having yellow seed coat is cultivated in small packets of North Eastern Transitional Zone of Karnataka consisting of Bidar district. In general mung bean is mostly grown under dry land farming systems where erratic rains often expose the crop under moisture stress (Azab, 1997). Due to short duration and wide adaptability, it is grown throughout the year in double and multiple cropping systems. It is also grown as a mixed, inter and relay crop (Chakravorty and Khanikar, 2002).

Crop varieties or genotypes grown in different environments would frequently encounter significant fluctuations in yield performance. The fluctuations of crop performance with changing environments, technically termed as genotype and environment $(\mathrm{G} \times \mathrm{E})$ interaction, potentially presents limitations on selection and recommendation of varieties for target set of environments. The $\mathrm{G} \times \mathrm{E}$ interactions have immense importance in breeding programmes for identifying stable genotypes that are widely or specifically adapted to unique environments (Verma et al., 2008). The assessment of stability and wider adaptability of breeding lines against biotic and abiotic stresses is a pre requisite in any breeding programme. Various workers emphasized the importance of genotypes over environment, the linear regression of genotypes over environmental index and the deviation from regression coefficient for determination of stability and adaptation of genotypes for yield and other important yield contributing traits in mung bean (Abbas et al., 2008). Stability in performance of a genotype over a wide range of environment is a desirable attribute and depends upon the magnitude of the GE interactions. Abbas et al. (2008) carried out stability analysis in mung bean and indicated that GE interactions were highly significant and were cross over in type.

The yield of mung bean fluctuates due to suitability of varieties to different growing environments. A specific genotype does not always exhibit the same phenotypic traits under all environments and different genotypes respond differently to specific location (Kamannavar et al., 2011). Therefore, knowledge of $\mathrm{G} \times \mathrm{E}$ interaction and yield stability are important for breeding new cultivars with improved adaptation to environmental constraints prevailing in the target environments. In view of this, the present studies were conducted to know genotype-environment interaction and to identify stable and high yielding yellow mung bean genotypes under changing environments.

\section{MATERIALS AND METHODS}

The materials for the present investigation consists of nine genotypes of yellow mung $V$. radiata and three 
genotypes of green gram (Table 1) evaluated during kharif season of the years 2007, 2010 and 2011 at Agricultural Research Station, Bidar, Karnataka state, which consists of north eastern transitional zone (Zone 1) having medium black clay laterite soil type. The mean annual rainfall is $937.3 \mathrm{~mm}$. The experiments were conducted in randomized block design replicated thrice in each year/environment with row spacing of $30 \mathrm{cms}$ and plant to plant distance of $10 \mathrm{cms}$. Recommended package of practices were followed for raising the good crop. The crop was harvested at the time of $90 \%$ pod maturity and yield data were recorded in $\mathrm{Kg} / \mathrm{Ha}$. Stability parameters were worked out as suggested by Eberhart and Russell (1966) using computer software written in "INDOSTAT"

\section{RESULTS AND DISCUSSION}

Stability analysis: Development of a stable variety is one of the major objectives of all breeding programmes. Phenotypic ally stable varieties are usually sought for commercial production of crop plants Several models were proposed for stability analysis. Stability is the ability to show a minimum interaction with the environment (Eberhart and Russell, 1966). Hence, the stability of genotype performance is directly related to the effect of $\mathrm{G} \times \mathrm{E}$ (Campbell and Jones, 2005). The adaptability of a variety over diverse environments is usually tested by the degree of its interaction with different environments under which it is tested (Finlay and Wilkinson, 1963). A variety or genotype is considered to be more adaptive/stable one, if it has high mean yield but a low degree of fluctuation in yielding ability when grown over diverse environments. A specific genotype does not always exhibit the same phenotypic traits under all environments and different genotypes respond differently to specific location.

Therefore, knowledge of $\mathrm{G} \times \mathrm{E}$ interaction and yield stability are important for breeding new cultivars with improved adaptation to environmental constraints prevailing in the target environments. The present research studies were conducted to know genotype -environment interaction and to identify stable and high yielding yellow mung bean genotypes under changing environments.

Pooled analysis of variance for stability of yield (Table 2) revealed the existence of substantial variability among the genotypes for seed yield. Significance of genotype $x$ year interaction revealed that genotypes interacted significantly with environments/years (Singh et. al., 2013) The partitioning of interaction showed that both linear and non linear (pooled deviation) components of interaction were highly significant indicating that both predictable and unpredictable components shared $\mathrm{G} \times \mathrm{E}$ interaction. The $\mathrm{G} \times \mathrm{E}$ (linear) interaction was highly significant when tested against pooled deviation, which revealed that there are genetic differences among genotypes for their regression on the environmental index. These results are in agreement with those reported by Natarajan (2001) in black gram (Vigna mungo L.) and Manivannan et al. (1998), Patel et al. (2009) and Kamannavar et al. (2011) in green gram (Vigna radiata L ).

Eberhart and Russel (1966) and Westerman (1971) emphasized that both linear (bi) and non-linear $\left(\mathrm{S}^{2} \mathrm{di}\right)$ components of G X E interaction should be considered in judging the phenotypic stability of a particular genotype. From the ANOVA table, the value for the genotype $\times$ environment (linear) sum of squares was not as a

Table 1. Ancillary data of genotypes of yellow moong (V. radiata $\mathrm{L}$ ).

\begin{tabular}{lccccccc}
\hline Genotype & $\begin{array}{c}\text { Days to } \\
\mathbf{5 0 \%}\end{array}$ & $\begin{array}{c}\text { Days to } \\
\text { maturity }\end{array}$ & $\begin{array}{c}\text { Plant } \\
\text { height } \\
\text { flowering }\end{array}$ & $\begin{array}{c}\text { Pods/ } \\
\text { plant }\end{array}$ & $\begin{array}{c}\text { Pod length } \\
\text { (cm) }\end{array}$ & $\begin{array}{c}\text { Seeds } \\
\text { /pod }\end{array}$ & $\begin{array}{c}\text { 100 seed } \\
\text { wt } \\
\text { (gram) }\end{array}$ \\
\hline Yellow mung-1 (YM-1) & 32 & 60 & 50.2 & 19.2 & 8.0 & 11.4 & 3.64 \\
Yellow mung-2 (YM-2) & 32 & 58 & 48.4 & 21 & 7.8 & 12.2 & 3.00 \\
Yellow mung-3 (YM-3) & 32 & 59 & 52.6 & 20.6 & 7.8 & 12.0 & 3.42 \\
Yellow mung-4 (YM-4) & 33 & 60 & 47.4 & 20.0 & 8.2 & 12.6 & 3.40 \\
Yellow mung-5 (YM-5) & 33 & 60 & 48.0 & 18.2 & 6.8 & 12.6 & 2.82 \\
Yellow mung-6 (YM-6) & 33 & 58 & 56.6 & 17.6 & 7.0 & 11.8 & 3.30 \\
Yellow mung-7 (YM-7) & 33 & 64 & 47.6 & 16.8 & 7.2 & 12.0 & 3.38 \\
Yellow mung-8 (YM-8) & 32 & 60 & 44.4 & 17.0 & 7.4 & 12.0 & 3.20 \\
Yellow mung-9 (YM-9) & 31 & 63 & 50.6 & 16.4 & 7.2 & 12.2 & 3.50 \\
Sel-4 & 32 & 65 & 57.8 & 18.6 & 9.6 & 12.0 & 3.94 \\
BGS-9 & 33 & 66 & 60.0 & 17.2 & 12.8 & 14.0 & 4.56 \\
China mung & 31 & 65 & 53.6 & 17.0 & 9.8 & 12.6 & 4.30 \\
\hline
\end{tabular}


Table 2. Pooled analysis of variance for grain yield of yellow mung (V. radiata L.).

\begin{tabular}{lcc}
\hline Source of variance & DF & $\begin{array}{c}\text { Mean sum of } \\
\text { squares }\end{array}$ \\
\hline Replication with error & 06 & 4245.515 \\
Genotype & 11 & $8723.315 *$ \\
$\begin{array}{l}\text { Environment }+ \\
\text { (Genotype } \times \text { Environment) }\end{array}$ & 24 & $83282.234 * * *$ \\
Environment & 02 & $965461.552^{* * *}$ \\
Genotype $\times$ Environment & 22 & 3084.114 \\
Environment (Linear) & 01 & $1930923.105^{* * *}$ \\
Genotype $\times$ Environment & 11 & 3327.262 \\
(Linear) & 12 & $2604.219 *$ \\
Pooled deviation & 66 & 1082.956 \\
Pooled error & & \\
\hline
\end{tabular}

*Significance at $5 \%$ level, ** Significance at $1 \%$ level

large portion of the $\mathrm{G} \times \mathrm{E}$ interaction, when compared with the environment $\mathrm{E}$ (linear) sum of squares and the residual. Table 2 shows the variation among the genotypes and $\mathrm{G} \times \mathrm{E}$ interaction was significant. It means that genotypes exhibited different performance in different years /environments which is due to their different genetic makeup or the variation due to the environments or both.

The environmental indices for grain yield indicated that the year 2007 (215.852) followed by year 2011 (105.407) were the most favourable environments for the better expression of traits as revealed by high and positive environmental indices, while, the year 2010 (-321.259) was unfavourable environment due to high negative environmental indices (Table 3 ).

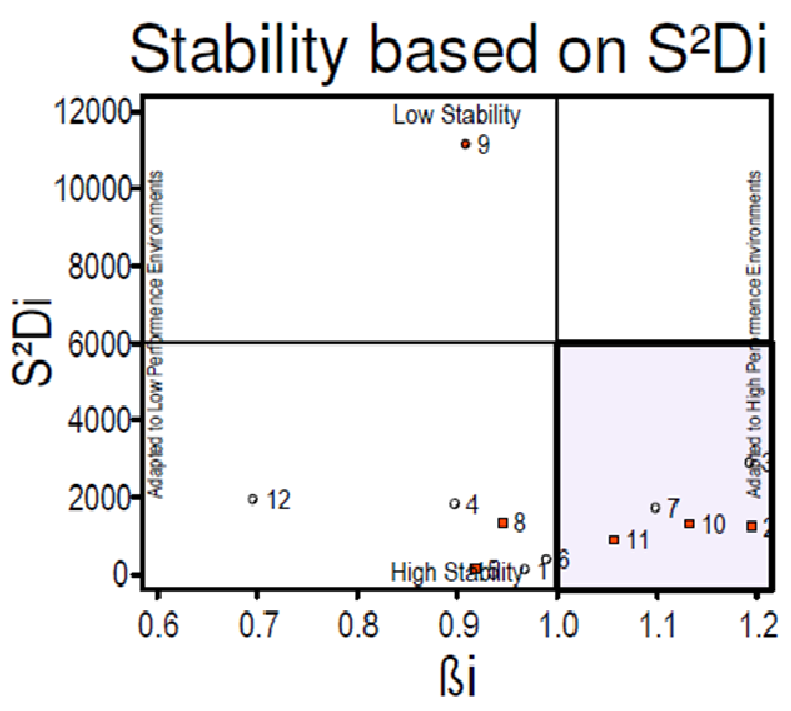

Fig. 1. Stability of (Vigna radiata L ) genotypes based on $S^{2}$ Di values.
The promising genotypes during the year 2007 were BGS-9 (846.667 Kg/Ha) followed by YM-3 (761.667 $\mathrm{Kg} / \mathrm{Ha})$ and Sel-4 (760.000 Kg/Ha). In the year 2010 the genotypes China mung (232.333) followed by BGS -9 (267.333) and YM- 4 (180.333) performed better. The genotypes namely, BGS-9 (605.444 Kg/Ha) followed by China mung $(537.889 \mathrm{Kg} / \mathrm{Ha})$ and Sel-4 $(519.778 \mathrm{Kg} / \mathrm{Ha})$ performed better in the year 2011 .

According to Eberhart and Russell (1966) model, a stable variety is one which has above average mean yield, a regression coefficient of unity $(b i=1)$ and non significant mean square for deviations from regression $\left(\mathrm{S}^{2} \mathrm{di}=0\right)$. High value of regression (bi>1) indicates that the variety is more responsive for input rich environment, while, low value of regression (bi<1), is an indication that the variety may be adopted in poor environment. The phenotypic stability of genotypes was estimated by mean performance over years (x), the regression coefficient (b) and deviation from regression. Based on stability parameters the genotypes YM-5 (459.889 Kg/Ha), YM-8 (451.333 Kg/Ha) exhibited low mean performance along with regression value nearer to unity $(\mathrm{bi}=1)$ and non significant deviation from regression $\left(\mathrm{s}^{2} \mathrm{di}=0\right)$ indicating the high stability and wider adaptability across the three environments. The genotypes BGS-9 $(605.444 \mathrm{Kg} / \mathrm{Ha})$ and Sel-4 (519.778 Kg/Ha) exhibited high mean value and bi values (bi>1) and non significant deviation $(\mathrm{s} 2 \mathrm{di}<0)$ value indicating adapted for high performance environments (Table 3 and Fig. 1).

Genotype YM-2 (457.556 Kg/Ha) exhibiting low mean performance but bi>1 and non significant deviation (s2 di < 0) and China mung (537.889 Kg/Ha) also exhibited high mean value but $\mathrm{bi}<1$ and significant deviation indicating adapted for low performance environments. The simultaneous consideration of these stability parameters for the individual genotype revealed that genotypes such as BGS-9, Sel-4 and China mung are high yielders and showed stable performance across the environments. The stability of genotypes for seed yield and its components in mung bean (Vigna radiata $\mathrm{L}$ ) has also been reported by Manivannan et al. (1998), and Patel et al. (2009) and Nath et al.(2013).

The presence of $\mathrm{G} \times \mathrm{E}$ interaction among the genotypes of yellow mung bean was revealed by present investigation. High yielding genotypes with wider adaptation and genotypes with specific adaptation to target environment were identified.

\section{Conclusion}

Stability in performance is one of the most desirable properties of a genotype to be released as a variety for wide cultivation. From the present study, it is concluded that, the genotypes BGS-9, Sel-4 and China mung are high yielders and showed stable performance across the environments may be useful in a breeding programme for evolving high yielding mung bean varieties well adopted to varying environments.

\section{REFERENCES}


Table 3. Mean performance and stability parameters for grain yield of yellow mung (V. radiata L.) cultivars over the seasons.

\begin{tabular}{|c|c|c|c|c|c|c|}
\hline \multirow[t]{2}{*}{ Genotype } & \multicolumn{4}{|c|}{ Grain yield (Kg/Ha) } & \multirow[t]{2}{*}{ bi } & \multirow[t]{2}{*}{$S^{2}$ di } \\
\hline & 2007 & 2010 & 2011 & Mean & & \\
\hline YM-01 & 690.000 & 152.667 & 530.000 & 457.556 & 0.968 & 118.379 \\
\hline YM-02 & 723.333 & 077.000 & 577.667 & 459.333 & 1.195 & -1249.168 \\
\hline YM-03 & 761.667 & 091.333 & 539.667 & 464.222 & 1.193 & 2886.498 \\
\hline YM-04 & 688.333 & 180.333 & 511.000 & 459.889 & 0.898 & 1827.283 \\
\hline YM-05 & 636.667 & 159.333 & 583.667 & 459.889 & 0.918 & -128.122 \\
\hline YM-06 & 673.333 & 160.667 & 621.667 & 485.222 & 0.990 & 380.123 \\
\hline YM-07 & 616.667 & 051.667 & 572.000 & 413.444 & 1.099 & 1709.719 \\
\hline YM-08 & 656.667 & 148.000 & 549.333 & 451.333 & 0.945 & -1342.036 \\
\hline YM-09 & 543.333 & 106.000 & 598.000 & 415.778 & 0.909 & 11148.149 ** \\
\hline Sel-4 & 760.000 & 155.000 & 644.333 & 519.778 & 1.132 & -1300.896 \\
\hline BGS-9 & 846.667 & 267.333 & 700.333 & 605.444 & 1.057 & -890.683 \\
\hline China mung & 723.333 & 323.333 & 567.000 & 537.889 & 0.696 & 1933.349 \\
\hline Environmental index & 215.852 & -321.259 & 105.407 & & & \\
\hline $\mathrm{CV} \%$ & 09.486 & 19.377 & 11.515 & & & \\
\hline $\mathrm{CD} @ 5 \%$ & 111.367 & 51.259 & 113.649 & & & \\
\hline
\end{tabular}

Abbas, G., Manzoor, B., Mahmood, T., Siddique M. and Ahsanul, H.M.( 2008). Stability analysis for seed yield in Mung bean [Vigna radiata (L.) Wilczek]. J. Agric. Res., 46(3): 223-228

Azab, M.A. (1997). Salt tolerance of two varieties of Mung bean (Vigna radiata L. Wilczek). Zagazig. J. Agric. Res., 24: 11-21

Campbell, B.T. and Jones, M.A. (2005). Assessment of genotype $\mathrm{x}$ environment interactions for yield and fibre quality in cotton performance trials. Euphytica, 144: 69-78.

Chakravorty, A. and M. Khanikar, 2002. Studies on maize and pulse intercropping system during summer season. J. Agri. Sci. Soc. North East India, 15(2):188-191

Eberhart, S.A. and Russell, W.A. (1966). Stability parameters for comparing varieties. Crop Sci. 6:36-40.

Finlay, K.W. and Wilkinson, G.N. (1963). The analysis of adaptation in a plant breeding programme. Australian J. Agric. Res., 14:742-754.

Kamannavar, P.Y., Vijaykumar, A.G., Revanappa, S.B., Ganajaxi, M., Arunkumar, Kuchanur, P.H. and Salimath P.M. (2011). Genotype $\times$ Environment interaction in Mungbean (Vigna radiata (L.) Wilczek) cultivars grown in different agro-climatic zones of Karnataka, Electronic J. Pl. Breed. 2(4):501-505

Manivannan, N., Ramasamy, A and Natarajan, N. (1998). Phenotypic stability analysis in greengram. Indian J.
Agric. Sci., 68: 31-32.

Natarajan, C. (2001). Stability of yield and its components in blackgram. Madras Agric. J., 88:409-413,

Nath Anamika , Harer, P. N. and Utpal Dey (2013), Stability analysis and $\mathrm{G} \times \mathrm{E}$ interaction in Mungbean (Vigna radiata L. Wilczek): A review. African J. Agric. Res. 8 ( 26), 3340-3347

Patel, J.D. Naika, M.R. Chaudhari, S.B. Vaghelaa, K.O. and Kodappully, V.C. (2009). Stability analysis for seed yield in green gram (Vigna radiata L. Wilczek). Agric. Sci. Digest, 29: 24-27.

Singh Vijayata, Yadav Ram Kumar, Yadav Rajesh, Malik R. S., Yadav Neelam R., and Singh Jogendra (2013). Stability analysis in mung bean [Vigna radiata (L) wilczek] for nutritional quality and seed yield. Legume Res. - An International Journal, 36(1):56- 61

Verma, S.K., Tuteja, O.P. and Monga, D. (2008). Evaluation for Genotypes $\times$ Environment interaction in relation to stable genetic male's sterility based Asiatic cotton (Gossypium arborecium) hybrid of north zone. Ind. J. Agric. Sci., 78(4): 375-378.

Westerman, J.M.(1971). Genotype X environment interaction and developmental regulation in Arabidopsis thaliana II. Inbred lines analysis. Heredity, 26: 93-106. 